Prepared for: Surgery

June 2016

\title{
The Role of Extended Criteria Donors in Liver Transplantation for Nonalcoholic Steatohepatitis
}

\author{
Francesca M. Dimou, MD ${ }^{1,2}$ \\ Hemalkumar B. Mehta, $\mathrm{PhD}^{1}$ \\ Deepak Adhikari, $\mathrm{MS}^{1}$ \\ Robert C. Harland, $\mathrm{MD}^{3}$ \\ Taylor S. Riall MD, $\mathrm{PhD}^{3}$ \\ Yong-Fang Kuo, $\mathrm{PhD}^{1}$
}
Department of Surgery, The University of Texas Medical Branch, Galveston, TX ${ }^{1}$, Department of Surgery, University of South Florida, Tampa, $\mathrm{FL}^{2}$, Department of Surgery, University of Arizona, Tucson, Arizona ${ }^{3}$

Funding: UTMB Clinical and Translational Science Award \#UL1TR000071, NIH T-32 Grant \# T32DK007639, AHRQ Grant \# 1R24HS022134

\author{
Corresponding Author: \\ Francesca M. Dimou, M.D., M.S. \\ University of Texas Medical Branch \\ 301 University Blvd \\ Galveston, TX 77555 \\ Phone: 386-717-6865 \\ Email fdimou@health.usf.edu
}




\begin{abstract}
INTRODUCTION: Nonalcoholic steatohepatitis is expected to become the leading indication for liver transplantation. Use of extended criteria donors (ECD) may help with donor allocation in these patients. The objective of this study was to determine the use of ECDs in patients with NASH undergoing liver transplantation to stimulate a liverspecific predictive model for ECD use.

METHODS: The UNOS database was used to identify patients undergoing liver transplantation for NASH (2002-2014). Cox hazards models were created using: 1) UNOS ECD criteria (based on kidney allocation), 2) individual donor characteristics (age, sex, race, cause of death, BMI, cold ischemic time, and 3) the Kidney Donor Profile Index (KDPI) to examine the effect of ECDs on mortality and graft failure.

RESULTS: 4,387 patients underwent liver transplantation for NASH; 1,359 (30.9\%) patients received an ECD. Transplantation with ECD livers had comparable patient survival (HR 1.06, 95\% CI 0.91-1.23) between donor types but an increased risk of graft failure (HR 1.18, 95\% CI 1.03-1.36) compared to standard donors. Individual characteristics did not impact patient survival or graft failure. A $10 \%$ increase in KDPI was associated with a $28 \%$ increase in patient mortality (HR $1.28,95 \%$ CI $1.02-1.60)$ and $45 \%$ increase in graft failure (HR 1.45, 95\% CI 1.18-1.80).

CONCLUSION: Based on the current UNOS definition, ECDs in NASH were associated with similar overall survival but increased risk of graft failure. Given the shortage of organs, creation of an easily calculated, liver-specific model similar to the KDPI may help risk stratify patients and improve organ allocation.
\end{abstract}




\section{INTRODUCTION}

Worldwide, nonalcoholic fatty liver disease (NAFLD) accounts for $25 \%$ to $45 \%$

of chronic liver disease. ${ }^{1}$ Its prevalence continues to increase in parallel with the worsening obesity epidemic. It is estimated that $68 \%$ of adults in the United States are overweight or obese, which translates to approximately 75 to 100 million individuals having NAFLD. ${ }^{1}$ Furthermore, progression to nonalcoholic steatohepatitis (NASH) and liver failure is becoming a national problem. The proportion of liver transplants performed for NASH-related cirrhosis increased nearly 10-fold from 1.2\% in 2001 to 9.7\% in 2009. ${ }^{2} \mathrm{NASH}-\mathrm{related}$ cirrhosis is now the second most common indication for liver transplantation after hepatitis C. It is projected that NASH will supersede hepatitis C as the most common indication for liver transplantation by the year $2020{ }^{1-3}$

Patients with NASH present a unique challenge for clinicians. Given their obesity, they are more likely to have associated chronic disease, including cardiovascular disease, renal disease, and metabolic syndrome. ${ }^{3}$ The associated comorbidity coupled with increased BMI results in reluctance to transplant these patients. A previous study documented that specific organs targeted for morbidly obese patients were $16 \%$ more likely to be turned down than for non-obese patients. Also, when compared to other indications for liver transplantation, NASH patients were least likely to receive a liver transplant and more likely to experience 90 -day waitlist mortality. ${ }^{4}$

Given the increasing prevalence of NASH-related end-stage liver disease (ESLD) and the ongoing shortage of donor organs, the use of extended criteria donor (ECD) livers has the potential to increase the donor pool for patients with NASH. While ECD is clearly defined in kidney donors, the definition of ECD donors in liver transplantation 
remains unclear. Donor characteristics such as donor age, cause of death, cold ischemic time, and macrosteatosis have been associated with increased risk of graft failure. ${ }^{5,6}$ Currently, the United Network for Organ Sharing (UNOS) data registry uses the kidney allocation criteria, which defines an ECD as a deceased cardiac donor or brain death donor and either: a) $\geq 60$ years of age or b) aged 50-59 with two of the following: history of hypertension, creatinine $\geq 1.5$, or stroke being cause of death. In general, use of ECD livers has been shown to have increased rates of graft failure in patients undergoing liver transplant for hepatitis $\mathrm{C}^{7,8}$

The objective of this study was to describe a contemporary cohort of patients undergoing liver transplantation for NASH and determine whether receipt of an ECD liver or other donor factors are independent predictors of patient and graft survival. If overall survival and the risk of graft failure are similar with ECD livers, this has the potential to increase the donor pool and allow for earlier transplantation in NASH patients with lesser MELD scores.

\section{METHODS}

\section{Study Design/Data Source}

This was a retrospective longitudinal cohort study. The UNOS Registry is a large database with over 150,000 patients including adults and children. Data are available from 1987 to 2014; all transplantation centers and organ procurement organizations in the United States are required to electronically submit forms to UNOS. Information submitted includes the: a) Transplant Candidate Registration Form, containing patient information at time of listing; b) Deceased Donor Registration Form, containing donor information; c) Transplant Recipient Registration Form containing clinical information 
about the recipient before and after transplantation, treatment, and the patient's status at discharge from the hospital; and d) Transplant Recipient Follow-Up Form containing follow-up information on the recipient including clinical and treatment information. This information is entered into the Standard Transplant Analysis and Research file which includes records on each transplant the patient underwent with subsequent follow-up information. We used data from 2002 to 2014 given that NASH was not given a specific numeric diagnosis code until 2002; prior to $2002 \mathrm{NASH}$ was only provided as a text code. $^{9}$

\section{Cohort Identification}

Figure 1 depicts the cohort selection diagram. The following criteria were used to establish the final cohort: 1) $\geq 18$ years old undergoing first liver transplant, 2) primary diagnosis of NASH, and 3) patients were included if they received a liver from a deceased donor and had information on ECD status and 4) patients who had a secondary diagnosis of hepatitis $\mathrm{C}$ or alcoholic cirrhosis were excluded, because this may result in confounding.

Outcome

The primary outcomes in this study were overall survival and graft survival. Overall survival time was defined as transplant date to death date. Graft survival time was defined as transplant date to date of graft failure or re-transplant date.

\section{Exposure}

The UNOS transplant registry uses a specific variable that classifies donors as ECD, which UNOS has defined within the registry as a deceased cardiac donor or brain death donor and either: a) $\geq 60$ years of age, or b) aged 50-59 with two of the following: 
history of hypertension, creatinine $\geq 1.5$, or stroke being cause of death. These criteria are based on the kidney allocation classification of extended criteria donors and is applied to liver donors. As UNOS criteria are based on kidney donors, models were also created using: 1) individual donor characteristics including donor age, sex, race, cause of death, body mass index, cold ischemic time, and 2) the Kidney Donor Profile Index (KDPI). The KDPI is calculated as a cumulative risk with the previous year's donors being used as a reference population. If a donor's KDPI is $80 \%$, their risk of graft failure is greater than $80 \%$ of all donors recovered in the prior year of their transplant. ${ }^{10}$

\section{Covariates}

For all patients who underwent liver transplant, recipient and donor characteristics were identified and stratified based on donor type. Recipient characteristics included: age, sex, race, MELD at transplantation, body mass index (BMI), history of diabetes, months on the waitlist, and region.

Statistical Analysis

All analyses were performed using SAS 9.4 (SAS Institute, NC). Descriptive statistics were done to describe trends in diagnosis of NASH over the time period of the study (2002-2014) and utilization of extended criteria donors in patients with a diagnosis of NASH. Recipient and donor demographics were described with categorical variables and compared using chi-square. A logistic regression model of all patients who underwent liver transplantation for NASH was constructed to determine which factors were associated with greater likelihood of patients receiving an ECD versus standard liver donor. The model included the following recipient factors: age, sex, race, BMI, MELD score at transplantation, history of diabetes, waitlist time, and region. 
Using Kaplan-Meier curves, unadjusted survival rates were compared between patients who received a standard donor versus those who received an ECD. A log-rank test was used to compare significance between curves. Two, separate, Cox proportional hazards models were constructed for overall survival (risk of death) and graft survival (risk of graft failure). In the former, patients were censored if they were lost to follow-up or at the end of study time period, whichever came earlier. In the graft survival model, patients were censored if they died, were lost to follow-up, or at the end of study time period, whichever came earlier. Both models adjusted for: recipient age, sex, race, MELD, BMI, history of diabetes, months on the waitlist, and transplant region based on the allocation system of the Organ Procurement and Transplant Network. ${ }^{11}$

Different criteria have been used to define ECD livers. ${ }^{5,6}$ Based on these models, additional Cox proportional hazards models looking at patient survival and graft failure were created with the same recipient factors and individual donor factors based the prior literature. Two separate models were constructed which included either a) individual donor factors (donor age, sex, race, cause of death, donor BMI, and cold ischemic time) or b) KDPI.

The KDPI was used as an additional model to predict outcomes given its use in kidney transplantation; the KDPI scores donors based on a scale of 0-1.0 (reported as a percentage) rather than a binary classification. ${ }^{12}$ The score includes 10 specific donor factors that provide a profile index. Given that this approach may provide better specificity to ECDs and patient outcomes, this model was compared to the original model using only the binary UNOS ECD definition. 


\section{RESULTS}

\section{Trends and Patient Demographics}

From 2002 to 2014, the annual volume of liver transplants increased from 3,557 to 5,012. During this time period, there were 8,540 patients with NASH on the waiting list and 4,387 (51.4\%) patients underwent liver transplantation. Of those transplanted, $3,028(69.0 \%)$ received a standard donor and 1,359 (31.0\%) patients received an ECD based on UNOS criteria. From 2002 to 2014, the percentage of patients receiving liver transplantation for NASH increased from $<1 \%$ in 2002 to $13.3 \%$ in 2014 (Figure 2A). In 2014, $26.6 \%$ of patients undergoing liver transplant for NASH received an ECD. The percentage of ECDs used in NASH patients was relatively greater compared to all liver transplant patients (Figure 2B). Overall, the use of ECDs in NASH patients was stable over time $(\mathrm{p}=0.44$ for trend $)$.

When comparing recipient demographics based on donor type (Appendix A), patients who received a liver from an ECD were older ( $32 \%$ of patients $\geq 65$ years vs. $25.5 \%$ in patients $<50$ years of age; $\mathrm{p}<0.0034)$, spent a greater time on the waitlist ( $28.7 \%$ of patients waitlisted for $<3$ months vs. $33.5 \%$ waitlisted $>9$ months; $p=0.0006$ ), and had lesser MELD scores compared to those who received a standard donor liver (38.4\% of patients with MELD scores <20 vs. $18.7 \%$ of patients with MELD scores $\geq 40$; $\mathrm{p}<0.0001)$. Significant geographic variation in receipt of ECD livers was observed; patients residing in the southeast $(35.1 \%)$ and northeast $(35.1 \%)$ were more likely to receive an ECD liver compared to other regions $(\mathrm{p}<0.0001)$. There was no difference in sex, race, BMI, and presence of diabetes between recipients of ECD livers and non-ECD livers. 
By definition, ECDs were more likely to be older (40.1\% over 65 vs. $0 \%$ over 65 , $\mathrm{p}<0.0001)$, to die of stroke $(75.7 \%$ vs. $26.4 \%, \mathrm{p}<0.0001)$, and to have a BMI $<29(64.1 \%$ vs. $73.6 \% ; \mathrm{p}<0.0001)$ compared to standard donors. Cold ischemic time was not different between the two donor types $(\mathrm{p}=0.91)$ (Appendix B).

Receipt of an Extended Criteria Donor

Receipt of an ECD was associated strongly with MELD score (Appendix C), with increasing MELD scores being less likely to receive an ECD compared to those with MELD scores <20 (MELD $\geq 40$ : OR 0.41, 95\% CI 0.29-0.56). Patients aged 50-64 were also more likely to receive an ECD compared to those younger than 50 (OR 1.27, 95\% CI 1.04-1.55). The use of ECD livers was associated with lesser waitlist times (Table 3). Patients residing in the Southwest, Northwest, and Midwest regions were least likely to receive ECD compared to those in the Southeast (Table 3).

\section{Patient and Graft Survival}

The overall survival in patients undergoing liver transplantation for NASH was $89.8 \%$ survival at 1 year, $76.4 \%$ at 5 years, and $56.9 \%$ at 10 years. In the Kaplan-Meier curves comparing survival between donor types, there was no difference in survival between standard donors and ECDs ( $\mathrm{p}=0.86$; Figure 3A). After adjusting for recipient and donor factors, the Cox proportional hazards model still did not demonstrate a significant difference in survival between the two donor types (HR 1.06, 95\% CI 0.91-1.23) (Table 1). MELD scores between 30 and 39 (HR 1.82, 95\% CI 1.51-2.21) as well as scores $\geq 40$ (HR 1.92, 95\% CI 1.43-2.58) were associated with increased risk of mortality compared to those with MELD scores $<20$. 
Overall graft survival was $87.7 \%$ survival at 1 year, $74.5 \%$ at 5 years, and $57.4 \%$ at 10 years. When stratified by donor type, the unadjusted model demonstrated a trend toward a difference between the two groups ( $\mathrm{p}=0.06$; Figure $3 \mathrm{~B}$ ), while the adjusted Cox model did demonstrate risk of graft failure in those receiving an ECD compared to standard donor (HR 1.18; 95\% CI 1.03-1.36) (Table 1).

Individual donor factors including donor age, sex, race, cause of death, BMI, and cold ischemic time $\geq 6$ hours did not increase the risk of mortality and graft failure (Table 2). In contrast, similar recipient factors such as older age, MELD score, low BMI, and history of diabetes were again associated with increased risk. The greatest predictor of patient survival and graft failure was the KDPI, which was reported as a continuous variable. With every $10 \%$ increase in KDPI, there was a $28 \%$ increased risk of patient mortality (HR 1.28; 95\% CI 1.02-1.60) and 45\% increased risk of graft failure (HR 1.45; 95\% CI 1.18-1.80) (Table 3).

\section{DISCUSSION}

$\mathrm{NASH}$ is becoming rapidly the most common indication for liver transplantation and is expected to supersede hepatitis $\mathrm{C}$ in the near future. Although there has been a slight increase in the number of donors recovered and transplanted, the organ donor shortage remains critical. In the UNOS annual report in 2014, there were over 10,000 people registered on the waitlist, but only $63 \%$ of these patients underwent eventually a liver transplant. ${ }^{13}$ Previous studies have shown that the use of ECDs in hepatitis C patients leads to worse outcomes. ${ }^{7,8,14,15}$ To date, no studies have evaluated the outcomes of ECD livers in the NASH population. The use of ECDs in these patients may further close the organ shortage gap. 
Based on the UNOS ECD criteria which are based currently on the kidney allocation criteria, patient survival was comparable between donor types when using the UNOS definition, but graft survival was decreased with ECDs. Several other donor characteristics have been associated with graft failure and overall survival after liver transplantation, including donor age, cause of death, hepatitis C status, malignancy, infection, race, and donor height. ${ }^{5,6}$ In our analysis, these individual donor characteristics were not associated with either overall survival or graft failure. The reason for these findings are likely two-fold. Previous studies deeming specific donor characteristics as "high risk" focus primarily on hepatitis $\mathrm{C}$ and alcoholic cirrhosis, a markedly different population than those with $\mathrm{NASH} .^{7}$ Also, analyzing donors simply as ECD or not may not be an optimal predictor of outcomes. The KDPI measures the cumulative risk of kidney graft failure over a continuum and uses 10 specific donor factors (donor age, height, weight, ethnicity, history of hypertension, history of diabetes, cause of death, serum creatinine, hepatitis $\mathrm{C}$ status, and donation after circulatory death); the KDPI may also be applied to liver transplantation. Our data show that with every $10 \%$ increase in KDPI, there is $28 \%$ increased risk of patient mortality and $45 \%$ increased risk of graft failure. This observation suggests that classifying donors along a spectrum rather than simply categorizing them as standard versus extended criteria may allow for better risk stratification.

Developing a similar cumulative risk model specific to liver transplantation with inclusion of transplant indication and other donor factors relevant to liver transplantation, such as age, cause of death, race, graft type used (split versus partial), macrosteatosis, and 
donor height, ${ }^{6}$ may help better create a standard definition of "high risk" or "extended criteria" and allow for better allocation of organs to optimize outcomes.

In 2006, Feng and colleagues ${ }^{6}$ proposed a donor risk index based on donor characteristics and reported the index as a relative risk of graft failure, but calculators for liver transplantation have yet to be developed. Furthermore, this previous study did not report macrosteatosis as increasing the risk for graft failure. Given the increasing prevalence of nonalcoholic fatty liver disease in the general population, this affects ultimately the quality and quantity of potential donors; indeed, liver graft steatosis has been shown to be an important predictor of primary graft nonfunction. ${ }^{16,17}$ Consistent incorporation of this variable into the UNOS database may help future studies and will identify the impact of donor steatosis on transplant recipients with NASH.

We found no differences in overall patient survival or graft survival based on donor age. This finding is in contrast to a large retrospective study comparing outcomes in patients with hepatitis $\mathrm{C}$ and alcoholic liver cirrhosis that found that donor age exceeding 40 years of age resulted in inferior graft survival and that donor age exceeding 50 years of age impacted negatively patient survival in recipients with hepatitis C. ${ }^{14}$ Given our data, allocation of younger donors to those with hepatitis $\mathrm{C}$ and use of older donors in patients with NASH may help better allocate organs and relieve the organ donor shortage.

Our study had also shown that recipient BMI was an important predictor in posttransplant outcomes. An early study in 2002 included 18,000 liver transplant recipients in the UNOS database and found increased 5-year mortality in patients with BMI exceeding 35 and increased risk of 30-day, 1-year, and 2-year mortality in those with a BMI over 40. ${ }^{18}$ Based on these data, the American Association for the Study of Liver Diseases 
(AASLD) state morbid obesity (BMI $\geq 40)$ as a relative contraindication to liver transplantation. ${ }^{19}$ Our data show that patients with a BMI greater than 25 (and even with BMI $\geq 35$ ) had a slightly improved survival and less likelihood of graft failure compared to those with BMI $<25$, even after controlling for donor status.

Other reports including a large retrospective study using the UNOS database reported lesser survival rates only at extremely low or extremely high BMI. ${ }^{20,21}$ A more recent meta-analysis by Saab and colleagues included 13 studies and 76,000 patients with no reported difference in survival based on BMI. ${ }^{22}$ These studies, however, do not focus specifically on NASH patients. Given that our cohort were mostly overweight or obese, it may be hypothesized that at the time of transplant, those patients with NASH and low BMI is a result ongoing liver failure. This possibility compounded with diabetes may further complicate the clinical status and result in poor outcomes in those patients with NASH and a BMI <25 receiving an ECD; thus, specific to NASH patients, it might be argued that those with low BMI and diabetes should not receive ECDs.

As with any retrospective study, a limitation of this study includes selection bias. In the receipt of both liver transplantation and receipt of an ECD organ, there are multiple factors involved. Also, certain variables studied previously could not be factored into the model given missing information; these factors include donor serum sodium concentration, warm ischemic times, and donor macrosteatosis. ${ }^{23-25}$ These factors have been reported as clinically important negative predictors in previous reports, but our specific cohort had greater than half of the cohort with missing values; therefore, these variables could not be reliably imputed into the model. Future work toward consistent 
data collection of these variables in the dataset may provide invaluable information regarding donor characteristics and patient outcomes.

\section{CONCLUSIONS}

Our study is the first, to our knowledge, that analyzes survival and graft failure rates in patients with NASH and the role of the ECD. Simply using the standard definition of ECD shows comparable survival but indicates an increased risk of graft failure. Creation of a liver-specific model similar to the KDPI that is easily calculated may help risk stratify patients and improve organ allocation. Given the rising obesity epidemic and incidence of NASH patients, understanding the use of ECDs in these patients may be vital in alleviating organ-donor shortage. 


\section{REFERENCES}

1. Rinella ME. Nonalcoholic fatty liver disease: a systematic review. Jama. Jun 9 2015;313(22):2263-2273.

2. Charlton MR, Burns JM, Pedersen RA, Watt KD, Heimbach JK, Dierkhising RA. Frequency and outcomes of liver transplantation for nonalcoholic steatohepatitis in the United States. Gastroenterology. Oct 2011;141(4):1249-1253.

3. Patel YA, Berg CL, Moylan CA. Nonalcoholic Fatty Liver Disease: Key Considerations Before and After Liver Transplantation. Digestive diseases and sciences. Jan 272016.

4. Wong RJ, Aguilar M, Cheung R, et al. Nonalcoholic steatohepatitis is the second leading etiology of liver disease among adults awaiting liver transplantation in the United States. Gastroenterology. Mar 2015;148(3):547-555.

5. Durand F, Renz JF, Alkofer B, et al. Report of the Paris consensus meeting on expanded criteria donors in liver transplantation. Liver transplantation : official publication of the American Association for the Study of Liver Diseases and the International Liver Transplantation Society. Dec 2008;14(12):1694-1707.

6. Feng S, Goodrich NP, Bragg-Gresham JL, et al. Characteristics associated with liver graft failure: the concept of a donor risk index. American journal of transplantation : official journal of the American Society of Transplantation and the American Society of Transplant Surgeons. Apr 2006;6(4):783-790.

7. Berenguer M. Risk of extended criteria donors in hepatitis $C$ virus-positive recipients. Liver transplantation : official publication of the American Association for the Study of Liver Diseases and the International Liver Transplantation Society. Oct 2008;14 Suppl 2:S45-50.

8. Maluf DG, Edwards EB, Stravitz RT, Kauffman HM. Impact of the donor risk index on the outcome of hepatitis $\mathrm{C}$ virus-positive liver transplant recipients. Liver transplantation : official publication of the American Association for the Study of Liver Diseases and the International Liver Transplantation Society. Jun 2009;15(6):592-599.

9. Afzali A, Berry K, Ioannou GN. Excellent posttransplant survival for patients with nonalcoholic steatohepatitis in the United States. Liver transplantation: official publication of the American Association for the Study of Liver Diseases and the International Liver Transplantation Society. Jan 2012;18(1):29-37.

10. Organ Procurement and Transplantation Network: KDPI Calculator. 2016; https://optn.transplant.hrsa.gov/resources/allocation-calculators/kdpi-calculator/. Accessed May 18, 2016, 2016.

11. Organ Procurement and Transplant Network System. 2016; https://optn.transplant.hrsa.gov/converge/members/regions.asp. Accessed February 9, 2016, 2015.

12. OPTN: A Guide to Calculating and Interpreting the Kidney Donor Profile Index (KDPI). 2014; https://optn.transplant.hrsa.gov/media/1512/guide_to_calculating_interpreting_kd pi.pdf. Accessed May 14, 2016, 2016.

13. Kim WR, Smith JM, Skeans MA, et al. OPTN/SRTR 2012 Annual Data Report: liver. American journal of transplantation : official journal of the American 
Society of Transplantation and the American Society of Transplant Surgeons. Jan 2014;14 Suppl 1:69-96.

14. Mutimer DJ, Gunson B, Chen J, et al. Impact of donor age and year of transplantation on graft and patient survival following liver transplantation for hepatitis C virus. Transplantation. Jan 15 2006;81(1):7-14.

15. Yagci G, Fernandez LA, Knechtle SJ, et al. The impact of donor variables on the outcome of orthotopic liver transplantation for hepatitis C. Transplantation proceedings. Jan-Feb 2008;40(1):219-223.

16. de Graaf EL, Kench J, Dilworth P, et al. Grade of deceased donor liver macrovesicular steatosis impacts graft and recipient outcomes more than the Donor Risk Index. Journal of gastroenterology and hepatology. Mar 2012;27(3):540-546.

17. Spitzer AL, Lao OB, Dick AA, et al. The biopsied donor liver: incorporating macrosteatosis into high-risk donor assessment. Liver transplantation : official publication of the American Association for the Study of Liver Diseases and the International Liver Transplantation Society. Jul 2010;16(7):874-884.

18. Nair S, Verma S, Thuluvath PJ. Obesity and its effect on survival in patients undergoing orthotopic liver transplantation in the United States. Hepatology. Jan 2002;35(1):105-109.

19. Martin P, DiMartini A, Feng S, Brown R, Jr., Fallon M. Evaluation for liver transplantation in adults: 2013 practice guideline by the American Association for the Study of Liver Diseases and the American Society of Transplantation. Hepatology. Mar 2014;59(3):1144-1165.

20. Orci LA, Majno PE, Berney T, Morel P, Mentha G, Toso C. The impact of wait list body mass index changes on the outcome after liver transplantation.

Transplant international : official journal of the European Society for Organ Transplantation. Feb 2013;26(2):170-176.

21. Tanaka T, Renner EL, Selzner N, Therapondos G, Lilly LB. The impact of obesity as determined by modified body mass index on long-term outcome after liver transplantation: Canadian single-center experience. Transplantation proceedings. Jul-Aug 2013;45(6):2288-2294.

22. Saab S, Lalezari D, Pruthi P, Alper T, Tong MJ. The impact of obesity on patient survival in liver transplant recipients: a meta-analysis. Liver international : official journal of the International Association for the Study of the Liver. Jan 2015;35(1):164-170.

23. Cameron AM, Ghobrial RM, Yersiz H, et al. Optimal utilization of donor grafts with extended criteria: a single-center experience in over 1000 liver transplants. Annals of surgery. Jun 2006;243(6):748-753; discussion 753-745.

24. Figueras J, Busquets J, Grande L, et al. The deleterious effect of donor high plasma sodium and extended preservation in liver transplantation. A multivariate analysis. Transplantation. Feb 15 1996;61(3):410-413.

25. Verran D, Kusyk T, Painter D, et al. Clinical experience gained from the use of 120 steatotic donor livers for orthotopic liver transplantation. Liver transplantation : official publication of the American Association for the Study of Liver Diseases and the International Liver Transplantation Society. May 2003;9(5):500-505. 


\section{FIGURE LEGENDS}

Figure 1. Cohort selection diagram for patients undergoing liver transplantation (20022014) and received either a standard donor or extended criteria donor (ECD).

Figure 2. Patients undergoing liver transplant between 2002-2014. A) Percentage of patients with NASH B) Percentage of ECDs used in all liver transplant patients compared to only NASH patients.

Figure 3. Patients who underwent liver transplantation for NASH and received either a standard donor or ECD. A) Overall survival $(p=0.86), B)$ Graft survival $(p=0.06)$ 
Table 1. Cox proportional hazards model evaluating survival and graft failure in NASH patients who received a standard donor versus extended criteria donor based on UNOS criteria.

\begin{tabular}{|c|c|c|}
\hline & Risk of Mortality & Risk of Graft Failure \\
\hline & Hazard Ratio (95\% CI) & Hazard Ratio $(95 \% \mathrm{CI})$ \\
\hline Extended Criteria Donor (Ref: No) & $1.06(0.91-1.23)$ & $1.18(1.03-1.36)^{* *}$ \\
\hline \multicolumn{3}{|l|}{ Recipient Factors } \\
\hline \multicolumn{3}{|l|}{$\overline{\text { Age (Ref: <50) }}$} \\
\hline $50-64$ & $1.27(1.01-1.59)^{* *}$ & $1.17(0.95-1.44)$ \\
\hline$\geq 65$ & $2.02(1.58-2.59)^{* *}$ & $1.73(1.38-2.18)^{* *}$ \\
\hline Sex (Ref: Male) & $0.95(0.83-1.10)$ & $0.95(0.83-1.08)$ \\
\hline \multicolumn{3}{|l|}{ Race (Ref: White) } \\
\hline African American & $0.96(0.60-1.53)$ & $1.08(0.71-1.65)$ \\
\hline Hispanic & $0.89(0.69-1.15)$ & $0.93(0.73-1.19)$ \\
\hline Other & $0.70(0.41-1.20)$ & $0.69(0.41-1.16)$ \\
\hline \multicolumn{3}{|l|}{ MELD (Ref: <20) } \\
\hline $20-29$ & $1.10(0.93-1.30)$ & $1.09(0.93-1.28)$ \\
\hline $30-39$ & $1.82(1.51-2.21)^{* *}$ & $1.68(1.40-2.02)^{* *}$ \\
\hline$\geq 40$ & $1.92(1.43-2.58)^{* *}$ & $1.63(1.22-2.17)^{* *}$ \\
\hline \multicolumn{3}{|l|}{ Body Mass Index- $\mathrm{kg} / \mathrm{m}^{2}($ Ref: $<25)$} \\
\hline $25-29$ & $0.71(0.57-0.90)^{* *}$ & $0.70(0.56-0.88)^{* *}$ \\
\hline $30-34$ & $0.72(0.57-0.90)^{* *}$ & $0.75(0.61-0.93)^{* *}$ \\
\hline $35-39$ & $0.76(0.60-0.96)^{* *}$ & $0.80(0.64-1.00)$ \\
\hline$\geq 40$ & $0.73(0.54-0.98)^{* *}$ & $0.77(0.59-1.02)$ \\
\hline \multicolumn{3}{|l|}{ History of Diabetes (Ref: No) } \\
\hline Yes & $1.26(1.09-1.45)^{* *}$ & $1.21(1.06-1.39)^{* *}$ \\
\hline Unknown & $0.91(0.51-1.62)$ & $1.16(0.71-1.89)$ \\
\hline \multicolumn{3}{|l|}{ Waitlist Time (Ref: <3 months) } \\
\hline 3-6 months & $1.05(0.87-1.28)$ & $1.08(0.89-1.30)$ \\
\hline 7-9 months & $1.03(0.80-1.34)$ & $1.08(0.85-1.39)$ \\
\hline$>9$ months & $1.08(0.90-1.30)$ & $1.10(0.93-1.31)$ \\
\hline \multicolumn{3}{|l|}{ Region (Ref: Southeast) } \\
\hline Southwest & $0.90(0.63-1.31)$ & $0.81(0.57-1.17)$ \\
\hline West & $0.84(0.63-1.11)$ & $0.83(0.64-1.09)$ \\
\hline Northwest & $0.58(0.28-1.19)$ & $0.53(0.26-1.09)$ \\
\hline Midwest & $1.03(0.84-1.26)$ & $1.08(0.90-1.31)$ \\
\hline Northeast & $1.19(0.98-1.45)$ & $1.15(0.96-1.39)$ \\
\hline
\end{tabular}

**designates significant value 
Table 2. Cox proportional hazards model including individual donor characteristics and recipient characteristics to identify independent predictors of mortality and graft failure.

\begin{tabular}{|c|c|c|}
\hline & Risk of Mortality & Risk of Graft Failure \\
\hline & Hazard Ratio $(95 \% \mathrm{CI})$ & Hazard Ratio (95\% CI) \\
\hline \multicolumn{3}{|l|}{ Donor Factors } \\
\hline \multicolumn{3}{|l|}{$\overline{\text { Age (Ref: <40) }}$} \\
\hline $40-64$ & $0.99(0.84-1.18)$ & $1.07(0.91-1.27)$ \\
\hline $65-74$ & $1.05(0.81-1.36)$ & $1.13(0.88-1.45)$ \\
\hline$\geq 75$ & $1.15(0.77-1.71)$ & $1.37(0.95-1.97)$ \\
\hline Sex (Ref: Male) & $1.01(0.87-1.17)$ & $1.04(0.91-1.20)$ \\
\hline \multicolumn{3}{|l|}{ Race (Ref: White) } \\
\hline African American & $0.87(0.72-1.05)$ & $0.97(0.81-1.16)$ \\
\hline Hispanic & $1.08(0.84-1.39)$ & $1.10(0.86-1.40)$ \\
\hline Other & $1.04(0.69-1.57)$ & $0.99(0.66-1.48)$ \\
\hline \multicolumn{3}{|c|}{ Cause of Death (Ref: Other) } \\
\hline CVA/Stroke & $1.09(0.91-1.32)$ & $1.11(0.93-1.33)$ \\
\hline Head Trauma & $0.84(0.68-1.02)$ & $0.91(0.75-1.09)$ \\
\hline \multicolumn{3}{|c|}{ Body Mass Index- $\mathrm{kg} / \mathrm{m}^{2}$ (Ref: $<25$ ) } \\
\hline $25-29$ & $1.00(0.85-1.17)$ & $1.00(0.86-1.17)$ \\
\hline $30-34$ & $0.93(0.76-1.14)$ & $0.92(0.75-1.12)$ \\
\hline $35-39$ & $1.15(0.88-1.50)$ & $1.14(0.89-1.47)$ \\
\hline$\geq 40$ & $1.17(0.83-1.66)$ & $1.04(0.74-1.46)$ \\
\hline \multicolumn{3}{|c|}{ Cold Ischemic Time (Ref: <6 hours) } \\
\hline$\geq 6$ hours & $1.07(0.93-1.23)$ & $1.14(0.99-1.30)$ \\
\hline \multicolumn{3}{|l|}{ Recipient Factors } \\
\hline \multicolumn{3}{|l|}{ Age (Ref: <50) } \\
\hline $50-64$ & $1.27(1.01-1.59)^{* *}$ & $1.17(0.95-1.44)$ \\
\hline$\geq 65$ & $2.03(1.58-2.59)^{* *}$ & $1.74(1.39-2.19)^{* *}$ \\
\hline Sex (Ref: Male) & $0.95(0.83-1.10)$ & $0.94(0.83-1.08)$ \\
\hline \multicolumn{3}{|l|}{ Race (Ref: White) } \\
\hline African American & $0.95(0.59-1.51)$ & $1.06(0.69-1.62)$ \\
\hline Hispanic & $0.87(0.68-1.13)$ & $0.92(0.72-1.17)$ \\
\hline Other & $0.70(0.41-1.19)$ & $0.69(0.40-1.14)$ \\
\hline \multicolumn{3}{|l|}{ MELD (Ref: <20) } \\
\hline $20-29$ & $1.13(0.96-1.34)$ & $1.12(0.96-1.31)$ \\
\hline $30-39$ & $1.82(1.51-2.21)^{* *}$ & $1.71(1.42-2.06)^{* *}$ \\
\hline$\geq 40$ & $1.92(1.43-2.58)^{* *}$ & $1.67(1.25-2.23)^{* *}$ \\
\hline \multicolumn{3}{|c|}{ Body Mass Index- kg/m² (Ref: $<25)$} \\
\hline $25-29$ & $0.71(0.56-0.89)^{* *}$ & $0.71(0.56-0.88)$ \\
\hline $30-34$ & $0.71(0.57-0.89)^{* *}$ & $0.76(0.61-0.94)$ \\
\hline $35-39$ & $0.75(0.59-0.95)^{* *}$ & $0.79(0.63-0.99)^{* *}$ \\
\hline$\geq 40$ & $0.73(0.54-0.98)^{* *}$ & $0.78(0.59-1.03)$ \\
\hline \multicolumn{3}{|c|}{ History of Diabetes (Ref: No) } \\
\hline Yes & $1.26(1.09-1.46)^{* *}$ & $1.21(1.06-1.39)^{* *}$ \\
\hline Unknown & $0.85(0.48-1.52)$ & $1.10(0.67-1.79)$ \\
\hline \multicolumn{3}{|c|}{ Waitlist Time (Ref: <3 months) } \\
\hline 3-6 months & $1.05(0.87-1.28)$ & $1.08(0.89-1.29)$ \\
\hline
\end{tabular}




\begin{tabular}{|l|c|c|}
\hline 7-9 months & $1.04(0.80-1.35)$ & $1.09(0.85-1.40)$ \\
\hline$>9$ months & $1.08(0.90-1.30)$ & $1.10(0.93-1.31)$ \\
\hline Region (Ref: Southeast) & & $0.80(0.55-1.15)$ \\
\hline Southwest & $0.89(0.62-1.30)$ & $0.81(0.62-1.07)$ \\
\hline West & $0.82(0.62-1.30)$ & $0.54(0.26-1.11)$ \\
\hline Northwest & $0.59(0.29-1.21)$ & $1.06(0.88-1.29)$ \\
\hline Midwest & $1.02(0.84-1.25)$ & $1.13(0.94-1.36)$ \\
\hline Northeast & $1.17(0.96-1.43)$ & \\
\hline
\end{tabular}

**designates significant value

Table 3. Cox proportional hazards model including KDPI and recipient factors to identify independent predictors of patient mortality and graft failure.

\begin{tabular}{|c|c|c|}
\hline & Risk of Mortality & Risk of Graft Failure \\
\hline & Hazard Ratio (95\% CI) & Hazard Ratio $(95 \% \mathrm{CI})$ \\
\hline KDPI & $1.28(1.02-1.60)^{* *}$ & $1.45(1.18-1.80)^{* *}$ \\
\hline \multicolumn{3}{|l|}{$\underline{\text { Recipient Factors }}$} \\
\hline \multicolumn{3}{|l|}{ Age (Ref: <50) } \\
\hline $50-65$ & $1.27(1.01-1.59)^{* *}$ & $1.17(0.95-1.44)^{* *}$ \\
\hline$\geq 65$ & $2.01(1.58-2.58)^{* *}$ & $1.72(1.36-2.16)^{* *}$ \\
\hline Sex (Ref: Male) & $0.93(0.81-1.07)$ & $0.93(0.81-1.06)$ \\
\hline \multicolumn{3}{|l|}{ Race (Ref: White) } \\
\hline African American & $0.93(0.58-1.50)$ & $1.05(0.68-1.62)$ \\
\hline Hispanic & $0.88(0.68-1.14)$ & $0.93(0.73-1.18)$ \\
\hline Other & $0.70(0.41-1.20)$ & $0.69(0.41-1.16)$ \\
\hline \multicolumn{3}{|l|}{ MELD (Ref: <20) } \\
\hline $20-29$ & $1.11(0.94-1.31)$ & $1.10(0.94-1.29)$ \\
\hline $30-39$ & $1.86(1.53-2.25)^{* *}$ & $1.70(1.41-2.05)^{* *}$ \\
\hline$\geq 40$ & $2.00(1.49-2.69)^{* *}$ & $1.69(1.27-2.26)^{* *}$ \\
\hline \multicolumn{3}{|c|}{ Body Mass Index- kg/m² (Ref: $<25$ ) } \\
\hline $25-29$ & $0.70(0.56-0.88)^{* *}$ & $0.70(0.56-0.87)^{* *}$ \\
\hline $30-34$ & $0.70(0.56-0.88)^{* *}$ & $0.74(0.60-0.92)^{* *}$ \\
\hline $35-39$ & $0.75(0.59-0.95)^{* *}$ & $0.79(0.63-0.99)^{* *}$ \\
\hline$\geq 40$ & $0.73(0.55-0.98)^{* *}$ & $0.78(0.59-1.03)$ \\
\hline \multicolumn{3}{|c|}{ History of Diabetes (Ref: No) } \\
\hline Yes & $1.26(1.09-1.46) * *$ & $1.22(1.06-1.40)^{* *}$ \\
\hline Unknown & $0.91(0.51-1.62)$ & $1.15(0.71-1.88)$ \\
\hline \multicolumn{3}{|c|}{ Waitlist Time (Ref: $<3$ months) } \\
\hline 3-6 months & $1.05(0.87-1.28)$ & $1.08(0.89-1.30)$ \\
\hline 7-9 months & $1.05(0.81-1.36)$ & $1.10(0.86-1.41)$ \\
\hline$>9$ months & $1.08(0.90-1.30)$ & $1.11(0.93-1.32)$ \\
\hline \multicolumn{3}{|c|}{ Region (Ref: Southeast) } \\
\hline Southwest & $0.92(0.64-1.34)$ & $0.83(0.57-1.19)$ \\
\hline West & $0.84(0.63-1.12)$ & $0.84(0.64-1.10)$ \\
\hline Northwest & $0.60(0.29-1.23)$ & $0.55(0.27-1.13)$ \\
\hline Midwest & $1.03(0.84-1.27)$ & $1.08(0.89-1.31)$ \\
\hline Northeast & $1.18(0.97-1.44)$ & $1.14(0.95-1.38)$ \\
\hline
\end{tabular}


Appendix A. Recipient Demographics of Patients Receiving Either a Standard Donor or Extended Criteria Donor (ECD) based on the UNOS criteria.

\begin{tabular}{|c|c|c|c|}
\hline & $\begin{array}{c}\text { Standard Donor } \\
\mathbf{N = 3 , 0 2 8}(\text { column \%) }\end{array}$ & $\begin{array}{c}\text { Extended Criteria Donor } \\
\mathbf{N}=1,359 \text { (column \%) }\end{array}$ & p-value \\
\hline \multicolumn{4}{|c|}{ ( } \\
\hline$<50$ & $501(16.5)$ & $171(12.6)$ & 0.0034 \\
\hline $50-64$ & $1864(61.5)$ & $874(64.3)$ & \\
\hline$\geq 65$ & $663(22.0)$ & $314(23.1)$ & \\
\hline \multicolumn{4}{|l|}{ Sex } \\
\hline Female & $1382(45.6)$ & $635(46.7)$ & 0.51 \\
\hline Male & $1646(54.4)$ & $724(53.3)$ & \\
\hline \multicolumn{4}{|l|}{ Race } \\
\hline Caucasian & $2543(84.0)$ & $1162(85.5)$ & 0.24 \\
\hline African American & $77(2.5)$ & $22(1.6)$ & \\
\hline Hispanic & $330(10.9)$ & $139(10.2)$ & \\
\hline Other & $78(2.6)$ & $36(2.6)$ & \\
\hline \multicolumn{4}{|c|}{ Body Mass Index- kg/m $\mathrm{m}^{2}$} \\
\hline$<25$ & $309(10.2)$ & $138(10.1)$ & 0.65 \\
\hline $25-29$ & $652(21.5)$ & $292(21.5)$ & \\
\hline $30-34$ & $945(31.2)$ & $422(31.0)$ & \\
\hline $35-39$ & $767(25.3)$ & $366(26.9)$ & \\
\hline$\geq 40$ & $355(11.7)$ & $141(10.4)$ & \\
\hline \multicolumn{4}{|l|}{ MELD } \\
\hline$<20$ & $1061(35.0)$ & $662(48.7)$ & $<0.0001$ \\
\hline $20-29$ & $1084(35.8)$ & $473(34.8)$ & \\
\hline $30-39$ & $644(21.3)$ & $169(12.4)$ & \\
\hline$\geq 40$ & $239(7.9)$ & $55(4.0)$ & \\
\hline \multicolumn{4}{|l|}{ History of Diabetes } \\
\hline Yes & 1654 (54.6) & $749(55.1)$ & 0.94 \\
\hline No & $1331(44.0)$ & $590(43.4)$ & \\
\hline Unknown & $43(1.4)$ & $20(1.5)$ & \\
\hline \multicolumn{4}{|l|}{ Waitlist Time } \\
\hline$<3$ months & $1652(54.5)$ & $664(48.8)$ & 0.0006 \\
\hline 3-6 months & $461(15.2)$ & $258(19.0)$ & \\
\hline 7-9 months & $259(8.5)$ & $106(7.8)$ & \\
\hline$>9$ months & $656(21.8)$ & $331(24.4)$ & \\
\hline \multicolumn{4}{|l|}{ Region } \\
\hline Southeast & $609(20.1)$ & $329(24.2)$ & $<0.0001$ \\
\hline Southwest & $190(6.3)$ & $44(3.2)$ & \\
\hline West & $368(12.2)$ & $132(9.7)$ & \\
\hline Northwest & $68(2.2)$ & $11(0.8)$ & \\
\hline Midwest & $887(29.3)$ & $354(26.0)$ & \\
\hline Northeast & $906(29.9)$ & $489(36.0)$ & \\
\hline
\end{tabular}


Appendix B. Donor Demographics in Patients Classified Using the UNOS definition of Standard Donor and Extended Criteria Donor (ECD)

\begin{tabular}{|c|c|c|c|}
\hline & $\begin{array}{c}\text { Standard Donor } \\
\mathbf{N}=\mathbf{3 , 0 2 8}(\text { column \%) }\end{array}$ & $\begin{array}{c}\text { Extended Criteria Donor } \\
\mathbf{N}=1,359 \text { (column \%) }\end{array}$ & p-value \\
\hline \multicolumn{4}{|l|}{ Age } \\
\hline$<40$ & $1818(60.0)$ & $0(0)$ & $<0.0001$ \\
\hline $40-64$ & $1210(40.0)$ & $805(59.2)$ & \\
\hline $65-74$ & $0(0)$ & $435(32.0)$ & \\
\hline$\geq 75$ & $0(0)$ & $110(8.1)$ & \\
\hline \multicolumn{4}{|l|}{ Sex } \\
\hline Female & $1127(37.2)$ & $670(49.3)$ & $<0.0001$ \\
\hline Male & $1901(62.8)$ & $689(50.7)$ & \\
\hline \multicolumn{4}{|l|}{ Race } \\
\hline Caucasian & $2105(69.5)$ & $933(68.7)$ & 0.0002 \\
\hline African American & $507(16.7)$ & $282(20.7)$ & \\
\hline Hispanic & $315(10.4)$ & $96(7.1)$ & \\
\hline Other & $101(3.3)$ & $48(3.5)$ & \\
\hline \multicolumn{4}{|l|}{ Cause of Death } \\
\hline CVA/Stroke & $802(26.4)$ & $1029(75.7)$ & $<0.0001$ \\
\hline Head Trauma & $1355(44.7)$ & $123(9.1)$ & \\
\hline Other & $871(28.8)$ & $207(15.2)$ & \\
\hline \multicolumn{4}{|c|}{ Body Mass Index- kg/m² } \\
\hline$<25$ & $1221(40.3)$ & $415(30.5)$ & $<0.0001$ \\
\hline $25-29$ & $1009(33.3)$ & $456(33.6)$ & \\
\hline $30-34$ & $474(15.7)$ & $273(20.0)$ & \\
\hline $35-39$ & $195(6.4)$ & $135(9.9)$ & \\
\hline$\geq 40$ & $129(4.3)$ & $80(5.9)$ & \\
\hline \multicolumn{4}{|l|}{ KDPI } \\
\hline$\geq 80$ & $155(5.1)$ & $1093(80.4)$ & $<0.0001$ \\
\hline$<80$ & $2873(94.9)$ & $266(19.6)$ & \\
\hline \multicolumn{4}{|l|}{ Cold Ischemic Time } \\
\hline$\geq 6$ hours & $1320(43.6)$ & $595(43.8)$ & 0.91 \\
\hline$<6$ hours & $1708(56.4)$ & 764 (56.2) & \\
\hline
\end{tabular}


Appendix C. Adjusted odds ratios with 95\% confidence intervals from logistic regression predicting the odds of receiving an extended criteria donor (ECD) or standard donor.

\begin{tabular}{|c|c|}
\hline & $\begin{array}{l}\text { Receipt of Extended Criteria Donor } \\
\qquad(\mathrm{N}=4,387)\end{array}$ \\
\hline & OR $(95 \% \mathrm{CI})$ \\
\hline \multicolumn{2}{|l|}{ Age (Ref: <50) } \\
\hline $50-65$ & $1.27(1.04-1.55)^{* *}$ \\
\hline$\geq 65$ & $1.24(0.98-1.56)$ \\
\hline Sex (Ref: Male) & $1.09(0.96-1.25)$ \\
\hline \multicolumn{2}{|l|}{ Race (Ref: White) } \\
\hline African American & $0.79(0.48-1.29)$ \\
\hline Hispanic & $1.14(0.90-1.43)$ \\
\hline Other & $1.21(0.79-1.85)$ \\
\hline \multicolumn{2}{|l|}{ MELD (Ref: <20)* } \\
\hline $20-29$ & $0.72(0.62-0.83)^{* *}$ \\
\hline $30-39$ & $0.45(0.37-0.55)^{* *}$ \\
\hline$\geq 40$ & $0.41(0.29-0.56)^{* *}$ \\
\hline \multicolumn{2}{|c|}{ Body Mass Index- kg/m² $($ Ref: $\geq 40)$} \\
\hline $35-39$ & $1.15(0.90-1.45)$ \\
\hline $30-34$ & $1.11(0.88-1.40)$ \\
\hline $25-29$ & $1.14(0.89-1.46)$ \\
\hline$<25$ & $1.28(0.96-1.71)$ \\
\hline \multicolumn{2}{|c|}{ History of Diabetes (Ref: No) } \\
\hline Yes & $1.07(0.93-1.22)$ \\
\hline Unknown & $1.09(0.63-1.89)$ \\
\hline \multicolumn{2}{|c|}{ Waitlist Time (Ref: <3 months) } \\
\hline 3-6 months & $1.23(1.03-1.48)^{* *}$ \\
\hline 7-9 months & $0.95(0.74-1.22)$ \\
\hline$>9$ months & $1.14(0.96-1.35)$ \\
\hline \multicolumn{2}{|c|}{ Region (Ref: Southeast) } \\
\hline Southwest & $0.43(0.30-0.62)^{* *}$ \\
\hline West & $0.77(0.59-1.00)$ \\
\hline Northwest & $0.29(0.15-0.56)^{* *}$ \\
\hline Midwest & $0.74(0.61-0.89)^{* *}$ \\
\hline Northeast & $0.98(0.82-1.17)$ \\
\hline
\end{tabular}

*MELD score calculated ta time of transplant

**designates significant value 


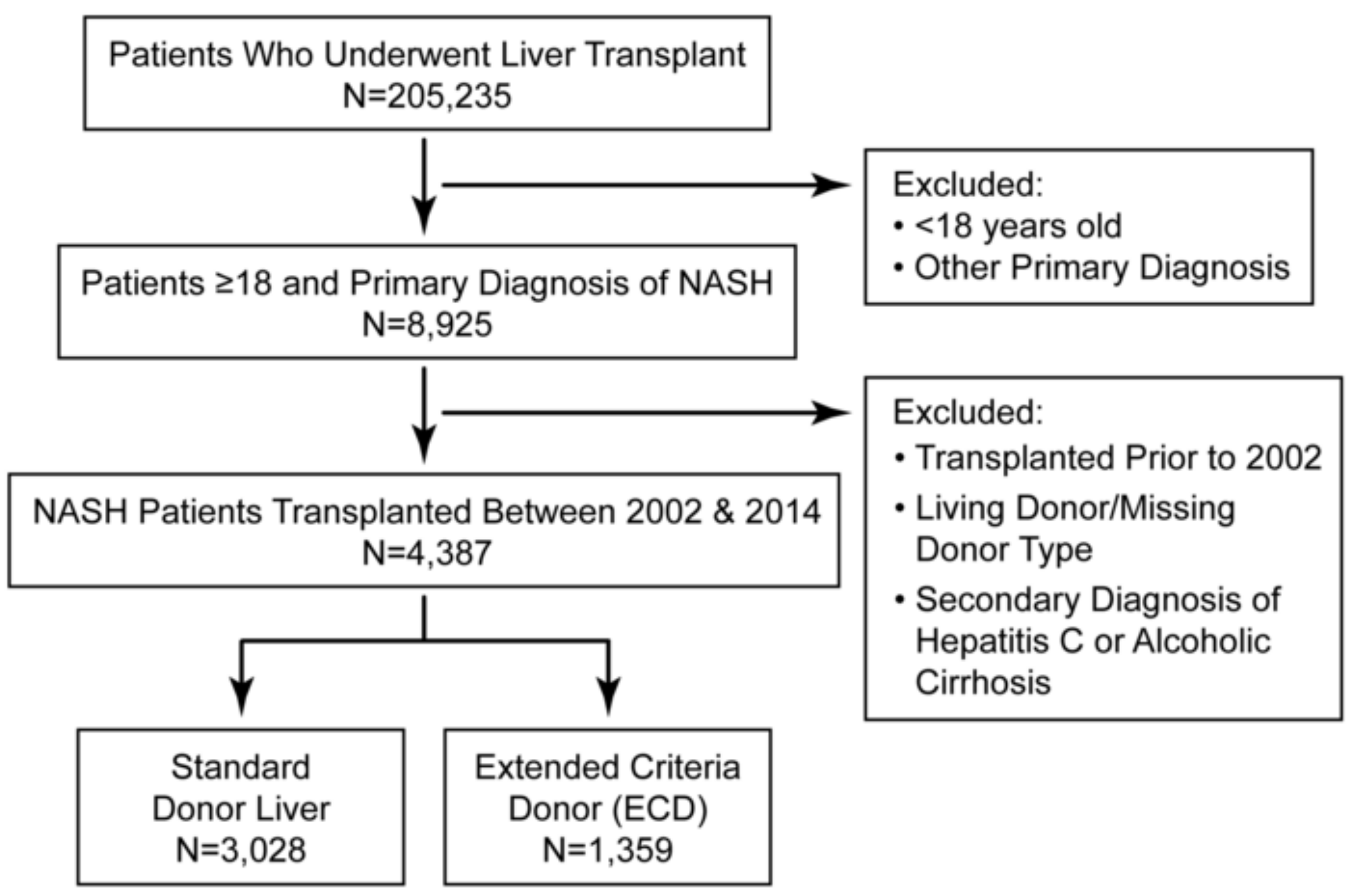


Click here to download high resolution image

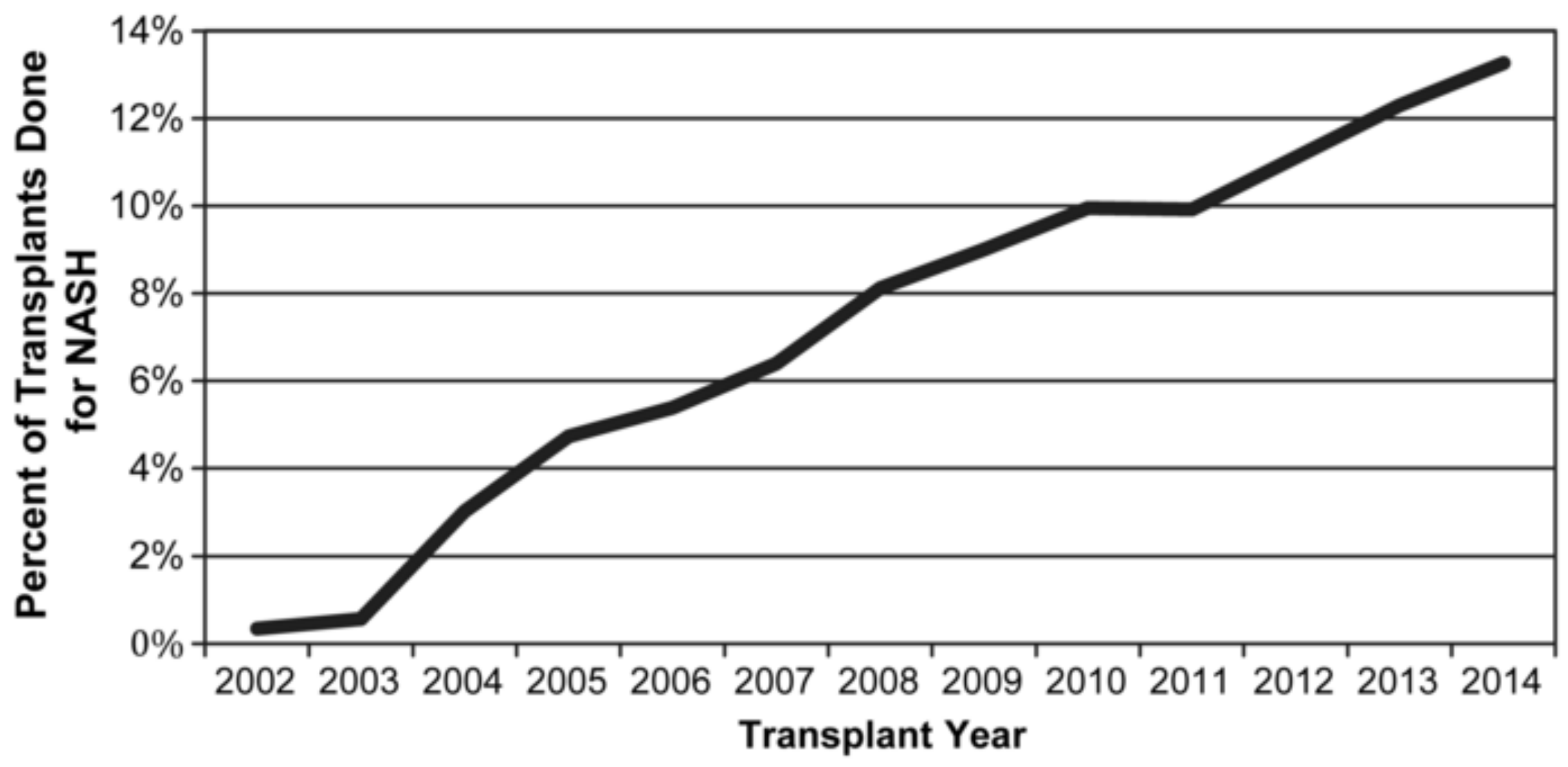




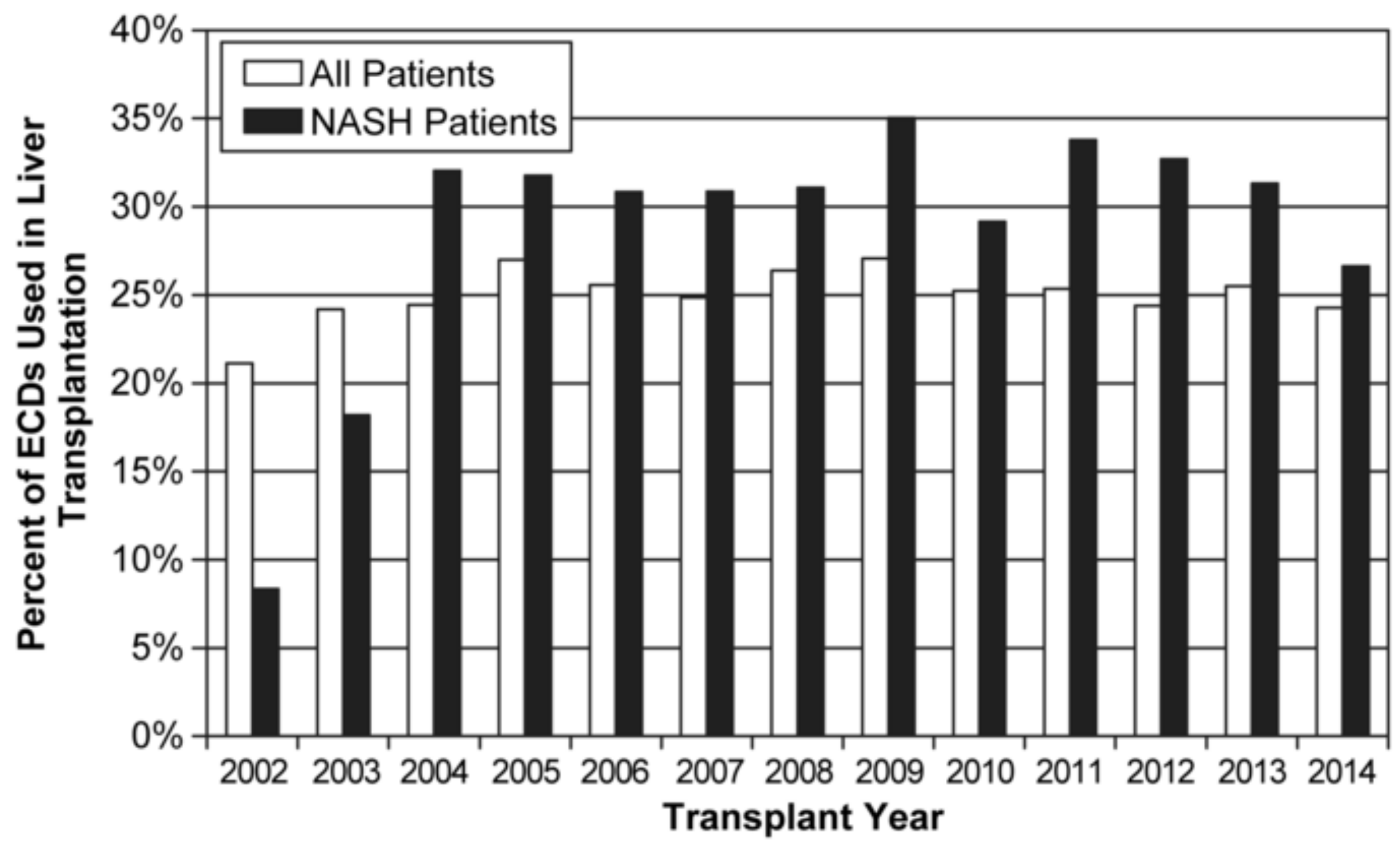




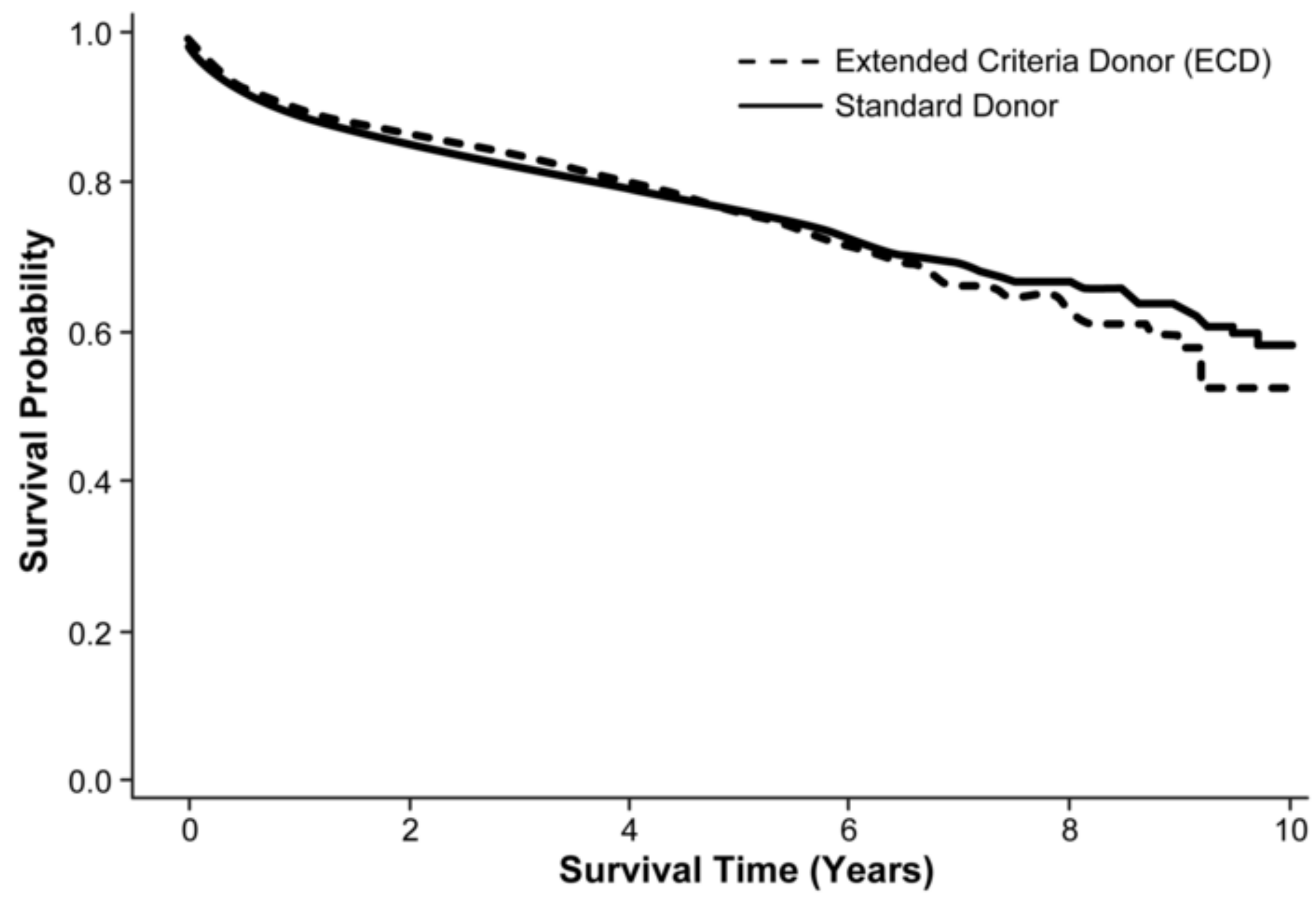




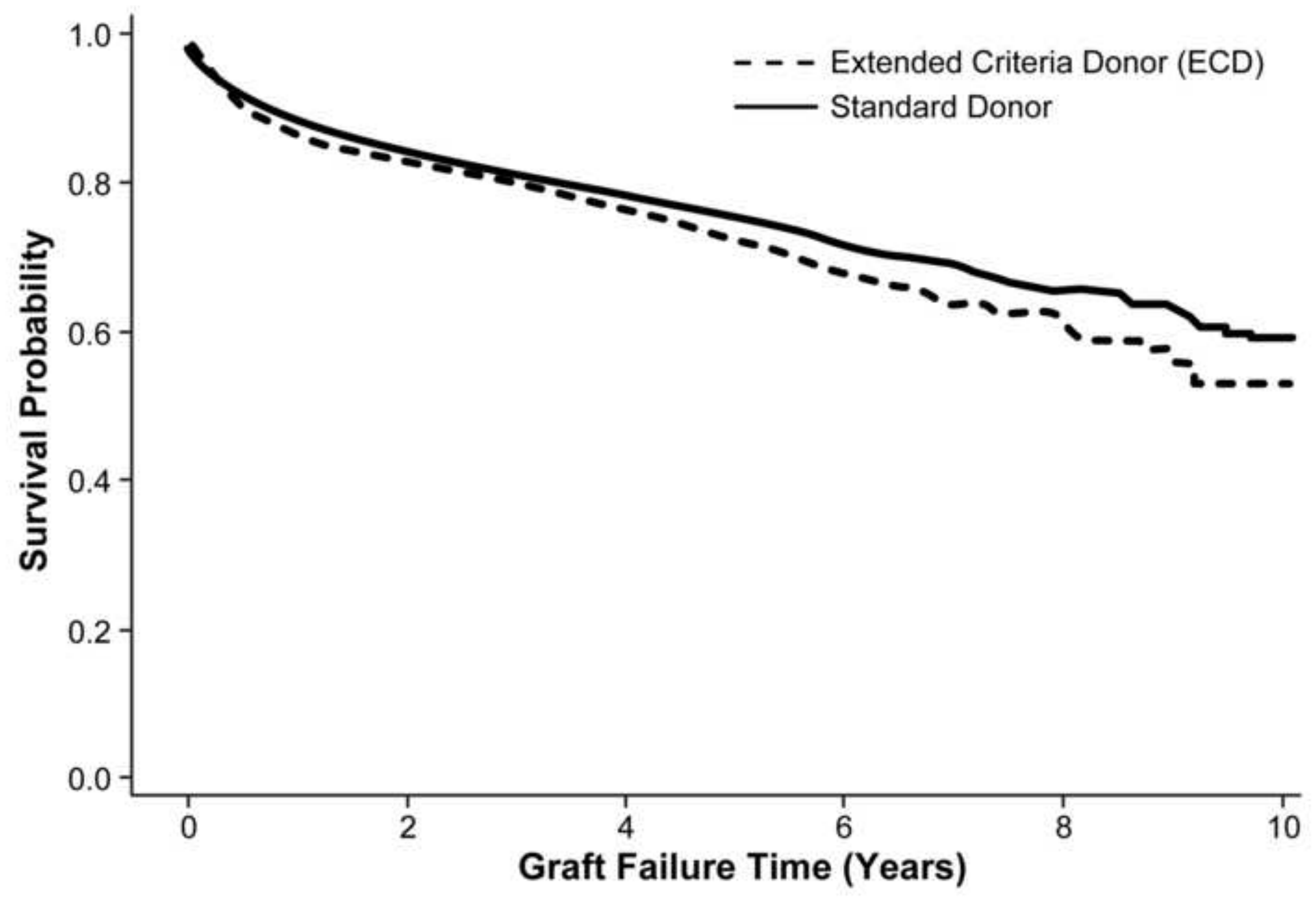


TOC Statement- 20160166

Using the UNOS database, we compared outcomes in NASH patients receiving either a standard donor or extended criteria donor (ECD). The findings are significant because the UNOS definition of ECD only identifies an increased risk of graft failure; however, use of a cumulative risk index may better risk stratify and allocate organ donors. 